\title{
Paving the Way for Social Learning when Governance is Weak: Supporting Dialogue between Stakeholders to Face a Groundwater Crisis in Morocco
}

\author{
Nicolas Faysse $*^{\mathrm{a}, \mathrm{b}}$, Mostafa Errahj ${ }^{\mathrm{b}}$, Amar \\ Imache $^{c}$, Hassane Kemmoun ${ }^{\mathrm{d}}$, and Taha Labbaci ${ }^{\mathrm{d}}$ \\ ${ }^{a}$ G-EAU Research Unit, CIRAD, Montpellier, France ; ${ }^{\mathrm{b}}$ Ecole Nationale \\ d'Agriculture de Meknès, Meknès, Morocco ; ${ }^{\mathrm{c}}$ LISODE, Montpellier, \\ France ; ${ }^{\mathrm{d}}$ Cap Rural, Meknès, Morocco; * Corresponding author
}

This is the post-peer reviewed version of the article with the same title, which has been published in Society and Natural Resources 27(3), 249-264, at http://www.tandfonline.com/doi/abs/10.1080/08941920.2013.847998

\begin{abstract}
Approaches to improve the governance of social-ecological systems are difficult to define in situations where governance is weak, i.e., those involving limited interactions between the actors, and weak management of natural resources. This paper analyzes an action research process implemented in the Chaouia coastal region of Morocco, where weak governance of the social-ecological system led to a groundwater and agricultural crisis. A dialogue between local actors was set up with the aim of identifying strategies to address the crisis. First separately and then together, farmers' groups and staff of public organizations analyzed the existing situation, scenarios for the future of the area, and strategies to cope with the crisis. Contrary to the expectations of the participants, farmers and staff of public organizations had productive discussions. This approach clarified how social learning can be achieved and governance improved in this situation of weak governance.
\end{abstract}

Key words foresight analysis, groundwater, Morocco, social learning, weak governance

\section{Introduction}

Weak governance of social-ecological systems poses challenges for both policy makers and researchers. Governance of social-ecological systems can be understood as the range of political, social, institutional, economic and administrative structures and processes that are in place to manage such systems (adapted from Rogers and Hall 2003). Bad, poor and weak governance have often been used as synonyms and defined in opposition to good governance, i.e., when the characteristics used to define good governance (e.g., Rametsteiner 2009) are not met. In cases where poor governance was defined per se (Armstrong 1994), the proposed definition was broad, with no specific reference to natural resources.

Here, we propose a more explicit definition of weak governance of social-ecological systems, i.e. the occurrence of weak interactions between the actors who use natural resources and the actors in charge of the management of these resources and of activities related to the use of 
the resources. These weak relations lead to insufficient management of natural resources and their uses, and sustainable management of the system is rarely discussed. Such weak interactions often stem from one or more of the following characteristics of the socialecological system: i) the actors' limited capacity to interact with others, ii) the actors' limited interest in being involved in the management of the social-ecological system and limited trust between the actors concerned, and iii) difficult and costly implementation of direct control of natural resources use. Our definition differs from the definition of poor governance cited by Armstrong (1994): "Arbitrary policy making, unaccountable bureaucracies, unenforced or unjust legal systems, the abuse of executive power, a civil society unengaged in public life, and widespread corruption". The definition cited by Armstrong refers to existing but dysfunctional institutions and relations between actors.

The governance of social-ecological systems involving groundwater use can often be considered as weak in developing countries (Shah 2009). This resource has specificities, such as unclear boundaries, a time lag between the cause and when overexploitation and pollution become apparent, and the high cost of measuring individual use when there are many users, all of which make it particularly difficult to manage (Theesfeld 2010). In developing countries, thousands and sometimes millions of farmers informally pump from the same aquifer. Farmer-led regulation of groundwater use has been observed in cases where the aquifer was smaller than 3,000 ha (van Steenbergen 2006). However, in the case of larger aquifers, community-based management of groundwater faces many constraints and sustainable groundwater management requires active collaboration between public authorities and water users (Ross and Martinez-Santos 2010). In large-scale aquifers in South Asia, the limited capacities of the public organizations responsible for water resource management have been compounded by lack of strong and representative associations of groundwater users. In these cases, the few policies set up to face groundwater overuse have usually been designed by governments with limited involvement of local actors (Shah 2009).

Possible ways to start improving weak governance of social-ecological systems are not easy to determine. Many theories of natural resources management assume that a series of elements defined as the "building blocks" of good governance are within reach. This was the case of Ostrom (1990), who considered that it was generally possible to create tools to monitor the use of natural resources, or to get resource users sufficiently organized to participate in the design of management rules. These theories provide limited guidance about where to start in order to improve the governance of the social-ecological systems when these building blocks are not within reach, at least not in the short term.

To help identify such ways, it may be useful to analyze the relevance of social learning, which has received increasing attention as a key component of sustainable natural resources management in recent years (Muro and Jeffrey 2008). Social learning can be defined as a "process of communicative action where multiple actors collectively learn about and develop an understanding of each others' interests, concerns, and preferences through dialogue and deliberation, thereby opening up new opportunities to arrive at a shared diagnosis of a specific environmental situation as a precursor to agreeing upon interventions and solutions" (Muro and Jeffrey 2012). Rist et al. (2006) found that social learning can help challenge stakeholders' assumptions and increase their understanding of the issues involved. Social learning can also help build trust among stakeholders and lead to concrete improvements in the management of water resources (Mostert et al. 2007).

Such a concept may inform approaches aimed at reinforcing governance in situations where governance is initially weak, as social learning strengthens relations between actors. However, implementing social learning in situations of weak governance cannot be taken for 
granted. As mentioned above, the actors' limited capacity or interest in interacting with other actors to manage the social-ecological system often leads to weak governance. These two characteristics of social-ecological systems jeopardize social learning in a much more profound way than the constraints that hinder the existing multi-stakeholder processes for water resource management in Europe assessed by Mostert et al. (2007).

In this paper, we analyze an action research project that set up a dialogue between local stakeholders in a situation of weak governance of the social-ecological system. The research took place in the Chaouia coastal region of Morocco, where the weak governance resulted in a groundwater and agricultural crisis. The study was carried out in the framework of the Aquimed project (2007-2010), which developed methods to support stakeholders in undertaking foresight analyses to assess interrelated agricultural development and groundwater management strategies in Mediterranean coastal regions.

First, we review approaches that attempted to initiate a multi-stakeholder dialogue in situations that were not favorable for such a dialogue. Second, we present the Moroccan case study in terms of the water resource, its uses, and the relations between actors that led to weak governance. Third, we describe the method used to set up a multi-stakeholder dialogue. Fourth, we describe the implementation of the dialogue, followed by the participants' evaluation of the process. Finally we discuss how this dialogue paved the way for social learning.

\section{Approaches to Initiate a Multi-Stakeholder Dialogue in Unfavorable Situations}

Different approaches to enable a multi-stakeholder dialogue have been tested in contexts involving one or more of the three above-mentioned characteristics of social-ecological systems that often result in weak governance.

Sultana and Thompson (2004) organized a dialogue involving all categories of users of a natural resource and, since most of the users did not belong to any particular organization, the researchers created groups. When actors show a lack of interest in natural resource management, capacity building may help raise awareness about the issues related to this resource (Ducrot 2009). To deal with the lack of trust between stakeholders, Baldwin and Ross (2012) held separate workshops with different groups of stakeholders in preparation for a joint meeting. During these separate workshops, participants had to 'put themselves into the skin' of other stakeholders. Finally, in situations where direct control of the use of natural resource is difficult and costly, indirect ways of influencing these uses may be considered (Shah 2009). In such situations, the participatory analysis of options to manage the socialecological system may benefit from the use of scenarios of changes in the system (Ravera et al. 2011). These scenarios may be constructed in collaboration with the stakeholders with the aim of fostering the actors' capacity for reflecting on their environment based on their own knowledge (Gidley et al. 2009).

All these approaches succeeded in implementing a dialogue between actors, which led to mutual learning. They did not lead to social learning as defined by Reed et al. (2010), but they managed to overcome some obstacles in the way of achieving social learning. 


\section{Case Study}

The information presented here comes from a preliminary analysis undertaken in 2008 and 2009. The analysis included interviews with actors and attendance by the research team at meetings between farmers and the staff of the Department of Agriculture and Sea Fishing (hereafter referred to as DoA) (see Bento et al. 2009 for more details on interviews with the farmers).

\section{Background}

The $1,200 \mathrm{~km}^{2}$ coastal Chaouia aquifer is located in the Doukkala-Abda region south-west of Casablanca. A $700 \mathrm{~km}^{2}$ study area was selected in the western part of the aquifer between the towns of Azemmour and Bir Jdid, in view of the fact that in the eastern part there is considerably less irrigated farming. Within this area (Fig. 1), the study focused on the area close to the seashore, since the southern part was not subject to groundwater overuse. The aquifer is recharged almost exclusively by rainfall infiltration. The aquifer is connected with seawater, and there is thus a risk of seawater intrusion in the case of groundwater overexploitation. The groundwater level and salinity rates are very sensitive to rainfall patterns (Younsi et al. 2001).

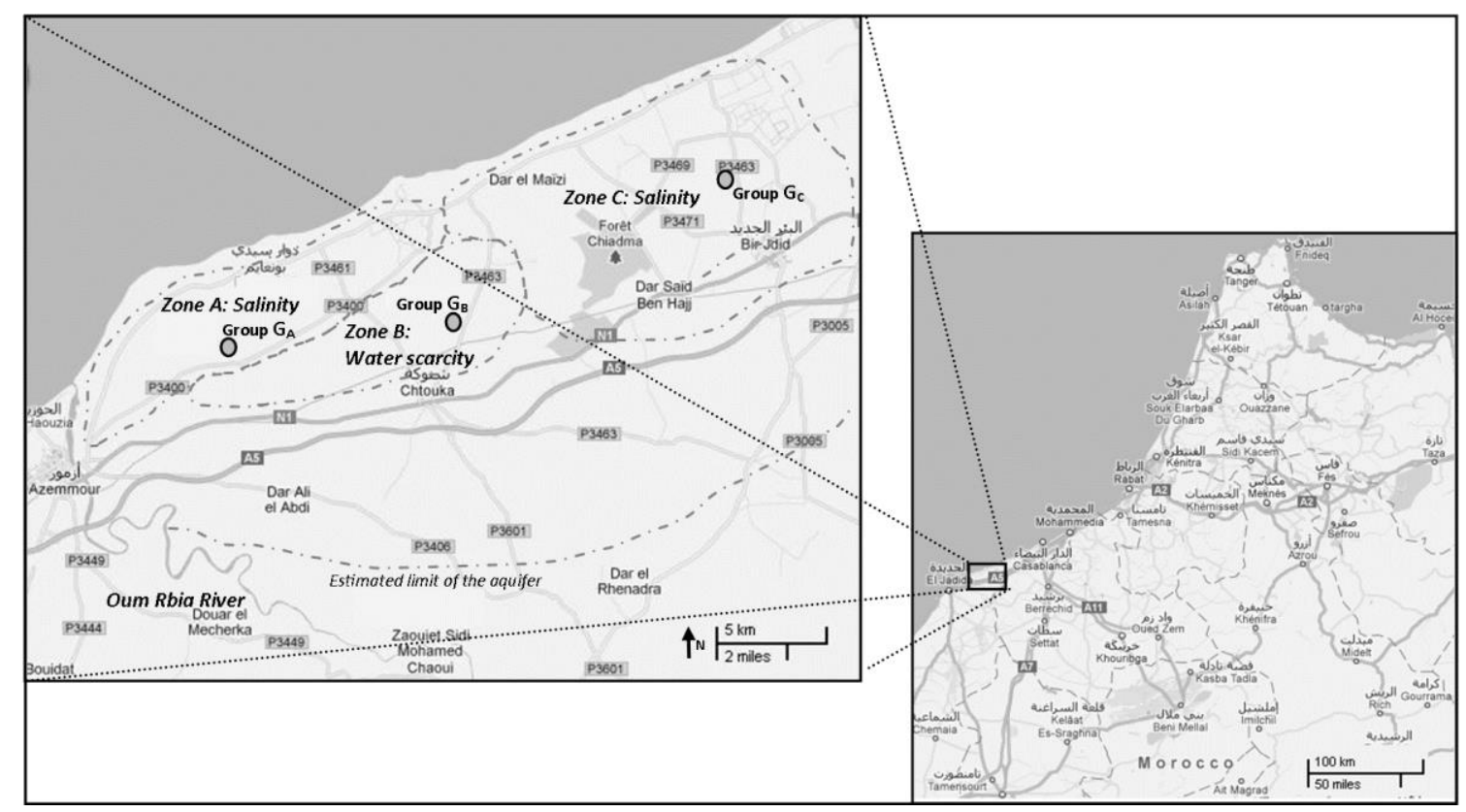

Figure 1. The part of the coastal Chaouia region studied, and the location of the farmers' groups involved in the multistakeholder process.

Large-scale use of groundwater for the irrigation of citrus and vegetables started in the 1960s. In the 1980s, the region experienced a golden age. This "Moroccan California", as it was known at the time, supplied the majority of vegetables produced in Morocco for export. The parastatal International Trade Office organized the production and export of the vegetables. Seawater intrusion, which was first observed in the 1980s, was the result of simultaneous groundwater overexploitation and drought. In the 1990s, the end of the International Trade 
Office's intervention and the spread of pests resulted in disorganization and weakening of the agricultural sector. Export of vegetables almost completely stopped. In addition, since the beginning of the 2000s, many farmers have been forced to reduce their activities in the inland part of the study area owing to falling groundwater levels. Despite this agricultural crisis, no large-scale development of tourism is planned for the coastal Chaouia region (with the exception of a small coastal fringe) in the next 15 years, neither is there a plan for industrial development. Consequently agriculture is likely to remain the main employment opportunity for inhabitants of the area.

In 2010, apart from a very limited number of boreholes for drinking water in rural communities, all the groundwater withdrawn was used for the irrigation of approximately 6,500 ha of farmland. Most of the area is equipped for drip irrigation. The Bouregreg Chaouia Catchment Management Agency (see below for a description of the agency) calculated the water deficit to be 10 million cubic meters per year. Three main zones can be delimited based on groundwater status (Fig. 1): in Zones A and C, groundwater has become saline, while in Zone $\mathrm{B}$, it has become scarce. In zone $\mathrm{A}$ and the coastal part of zone $\mathrm{C}$, groundwater salinization is being caused by seawater intrusion. In the inland part of zone $\mathrm{C}$, salinization also occurs but is due to the presence of salts in certain layers of the aquifer (Fakir et al. 2001). The limits of the zones are not precise and may overlap: in the area close to the limit between Zone A and Zone B, farmers are confronted with both water scarcity and salinity.

Berahmani et al. (2012) identified two main strategies used by farmers to cope with the groundwater crisis (related to either the quality or quantity of water) in the costal Chaouia region. Some farmers drilled new boreholes on their own or neighboring land to ensure access to sufficient fresh water. This strategy enabled them to continue with the same water intensive cropping systems. When fresh water was no longer available, often they moved to other areas or quit agriculture altogether. The majority of other farmers lacked the financial means for this strategy. They grew fewer vegetables and replaced vegetables by more saltresistant crops in the coastal area. They also increased rainfed crops and cattle rearing. Some sought part time or full time off-farm employment. During interviews, farmers had difficulty in formulating clear projects for the future, both for their own farms and for the communities in which they lived. Many farmers thought that there were no individual or collective ways to ensure sustainable agricultural activity in the region in the future.

The DoA was in charge of planning and supporting the development of the agricultural sector. In 2008, the DoA introduced a new policy for the agricultural sector called the Green Morocco Plan. As part of this policy, the DoA drew up its action plan for the Doukkala-Abda region in 2009 with very little input from farmers. The DoA intended to recreate the golden age of the 1980s. To this end, the DoA focused on two projects. First, water from the neighboring Oum Rbia River would be piped in to irrigate a 2,500 ha irrigation scheme in the southwestern part of the aquifer (corresponding approximately to Zone A). This project, which was designed in the 1990s, was never implemented owing to over allocation of water from the Oum Rbia River and lack of funding. The second project was to re-establish the activities of the International Trade Office to encourage the export of vegetables. In 2009, discussions began between the Trade Office and a group of experienced farmers. However, the two parties were unable to reach agreement on the terms of a partnership. In private discussion, many DoA staff expressed their doubts about the feasibility of the two projects. However, during the design of the regional action plan, the almost exclusive focus on the two projects limited discussion of possible alternatives. 


\section{Weak Governance of Groundwater Resources and of Their Uses}

Two catchment management agencies were responsible for the management of the aquifer, one for the area west of Bir Jdid, and the other for the eastern part. These agencies were independent authorities under the responsibility of the Ministry of Energy, Mines, Water and Environment. They were in charge of the management of surface and ground water resources in much larger catchments than the Chaouia aquifer. In application of the 1995 Water Law, both agencies had established that farmers who already had or wished to drill a well or a borehole in the Chaouia aquifer to a depth of more than $15 \mathrm{~m}$, had to register and obtain official authorization.

In practice, for both agencies, the aquifer was not a real priority, and the means at their disposal for intervening in the field were limited. Apart from monitoring piezometric levels and salinity rates, the two agencies were not active in the study area. In 2010, even though almost all existing wells and boreholes drilled in this aquifer were deeper than $15 \mathrm{~m}$, the drilling and use of wells and boreholes remained uncontrolled. Most farmers were not registered by catchment management agencies as groundwater users.

There were very few active farmers' organizations. The Chamber of Agriculture functioned at the regional level and its representatives mainly originated from the local rural elite. In practice, the Chamber had few links with grassroots farmers.

The DoA and the catchment management agencies previously had very few opportunities to meet owing to the absence of agency activities in the region. Moreover, after the state's withdrawal in the 1990s, most farmers almost never interacted with public organizations concerning their agricultural activities (for this reason, power relations were also limited). In the few meetings the DoA had with some of the farmers during our preliminary analysis, both the DoA staff and the farmers put forward their own scenarios for the future of the region. The farmers claimed that irrigated farming was doomed to disappear owing to the worsening groundwater and agricultural crisis. The administration's discourse was based on the official agricultural development plan, and no doubts were expressed about either the relevance of the plan or the possibility that it would not be implemented.

The administrative staff generally held the opinion that the farmers spent their time complaining rather than making proposals, and that there was consequently no point in discussing possible actions with them. Neither did the farmers expect much from interacting with public organizations. Many farmers recalled the time they had wasted during the many meetings held in attempts to restore the local activities of the International Trade Office, which ultimately failed. Overall, both parties considered their past encounters to be unsatisfying in terms of both content and outcome.

The staff of the DoA were not very knowledgeable about groundwater resources and uses, which were not their responsibility; nor were they particularly interested in the set up of a control over groundwater use. Neither did the farmers discuss the need to control groundwater use among themselves. In fact, the farmers thought that rainfall was much more important than the agricultural use of water in explaining the dynamics of groundwater levels and salinity rates (Bento et al. 2009). In Zone B, farmers were aware of the interdependence between neighboring boreholes, but most defended the right of farmers to freely use the water pumped on their own land.

The interrelated agricultural and groundwater sectors in the Chaouia area thus met the three characteristics of social-ecological systems listed in the introduction, and its governance can be described as weak. Governance was especially weak compared to governance at national 
level (with a historically strong administration) and compared to the governance of other Moroccan aquifers (Faysse et al. 2012a).

\section{Methodology}

A multi-stakeholder dialogue was organized with the aim of collectively identifying and analyzing strategies to face the agricultural crisis. The researchers chose an action research approach (Greenwood and Levin 2007), in the sense that, even though researchers designed the multi-stakeholder process, they teamed with local actors during the process to create knowledge on ways to improve the sustainability of the social-ecological system. The Aquimed team assumed the roles of facilitator, co-researcher and observer (Steyaert and Jiggins 2007). When facilitating the actors' collective thinking and production of ideas on how to tackle the agricultural crisis, the team left the stakeholders the choice of the issues to be discussed. In particular, the research team considered that in the short term, prospects for regulation of groundwater usage were limited. For that reason, the team decided not to focus on this issue but to let the actors decide whether they wished to tackle it or not. The team also decided they would not challenge the assumption of many farmers that seawater intrusion was mostly due to drought.

\section{Getting Stakeholders On Board}

Since the catchment management agency in the study area was not active, the main partner representing public organizations was the DoA. The project was presented to stakeholders as action research aiming at getting local actors to discuss ways of facing the agricultural crisis together. The team underlined the fact that the process had no planned links with decision making but pointed out to farmers that the process would provide an opportunity to discuss their ideas with staff from the DoA. After the project had been presented to senior staff of the regional DoA office, these staff decided that a group of engineers from the DoA should take part in the process. These relatively young DoA engineers occupied mid-level positions in the administration. They were interested in the process because they did not have much opportunity for internal open discussion about agricultural development strategies.

The team preferred to invite farmers who came from the same villages rather than attempting to ensure a wide range of farmers' profiles. Farmers who knew each other could more easily reach a common view of problems, scenarios, and possible solutions that they could later present to other actors (Faysse et al. 2012b). A group of farmers was identified in each of the three zones that had been previously defined based on groundwater status: 1) Group $G_{A}$ was made up of small-scale farmers from Zone A; 2) Group $G_{B}$ included farmers in Zone B who were specialized in vegetable growing; and 3) Group $G_{C}$ included larger-scale farmers from Zone C (Fig. 1). These farmers were of different ages and levels of education.

At the beginning of the process, some farmers lacked confidence in the research team, i.e., they felt the same way about the team as they felt about the public organizations with whom they usually interacted. To build their trust, the research team provided some support. The idea of creating a milk collection cooperative had been circulating for some time in Group $\mathrm{G}_{\mathrm{A}}$, and the team organized a visit to neighboring dairy units. A workshop on techniques for 
vegetable production was organized with members of Group $\mathrm{G}_{\mathrm{B}}$. Such activities also helped identify opportunities to support agricultural activities in both groups.

\section{Organization of the Workshops}

The research team chose not to have a joint meeting with all the actors at the outset. The failure of previous joint meetings in the region showed that preliminary work with each group of actors was indispensable. Thus, the process started with separate workshops for the farmers and DoA staff. The aim of these workshops was to prepare for a final regional workshop attended by both farmers and DoA staff. Each workshop brought together between eight and 30 participants.

The discussion of strategies to face the crisis was based on scenarios for the future of the agricultural sector in the study area. The preliminary analysis showed that both the farmers and the DoA tended to refer to the past when judging the current situation and envisaging possible futures. The scenario method was used to help both the farmers and the DoA to develop a number of alternatives that would not be limited either to confirming current dynamics or to reverting to a past situation. The scenarios were designed based on the identification of main drivers of change, and the assessment of their possible evolution situated approximately 15 years in the future. This corresponds to a rather short term future for scenarios involving the evolution of water resources and their management (March et al. 2012). This choice was made mainly because, for both farmers and the staff of public organizations, the region would already be quite different within a horizon of 15 years depending on the way the main drivers of change evolved (e.g., groundwater overexploitation or the construction of an irrigation scheme)(Faysse et al. 2012b). Moreover, the research team considered it a priority to improve the stakeholders' capacity to play an active role in the definition of possible futures. For that reason, building the scenarios together during the workshops was preferred to presenting scenarios based on expert knowledge and prepared in advance. These scenarios did not include quantitative assumptions, due to a lack of data and also to the fact they were designed during the workshops (Faysse et al. 2012b).

The first workshops with the three farmers' groups $\left(\mathrm{W}_{1} \mathrm{~F}\right.$, see Fig. 2) were devoted to analysis of past changes and current agricultural dynamics at the village level, and to ranking the factors that determined change. The second series of farmers' workshops was devoted to designing scenarios for agricultural development at the village level, at a horizon of several years, based on assumptions regarding the previously identified main driving factors of change. Farmers were invited to design separate scenarios for the evolution of each main driving factor of change. In parallel, during the first two workshops with the DoA staff (W1A and W2A), different driving factors were identified. As it was easier for the DoA staff than for the farmers to design global scenarios (the official development plan was already one of these scenarios) the DoA staff framed scenarios for the future of the agricultural sector using all the identified driving factors together. 


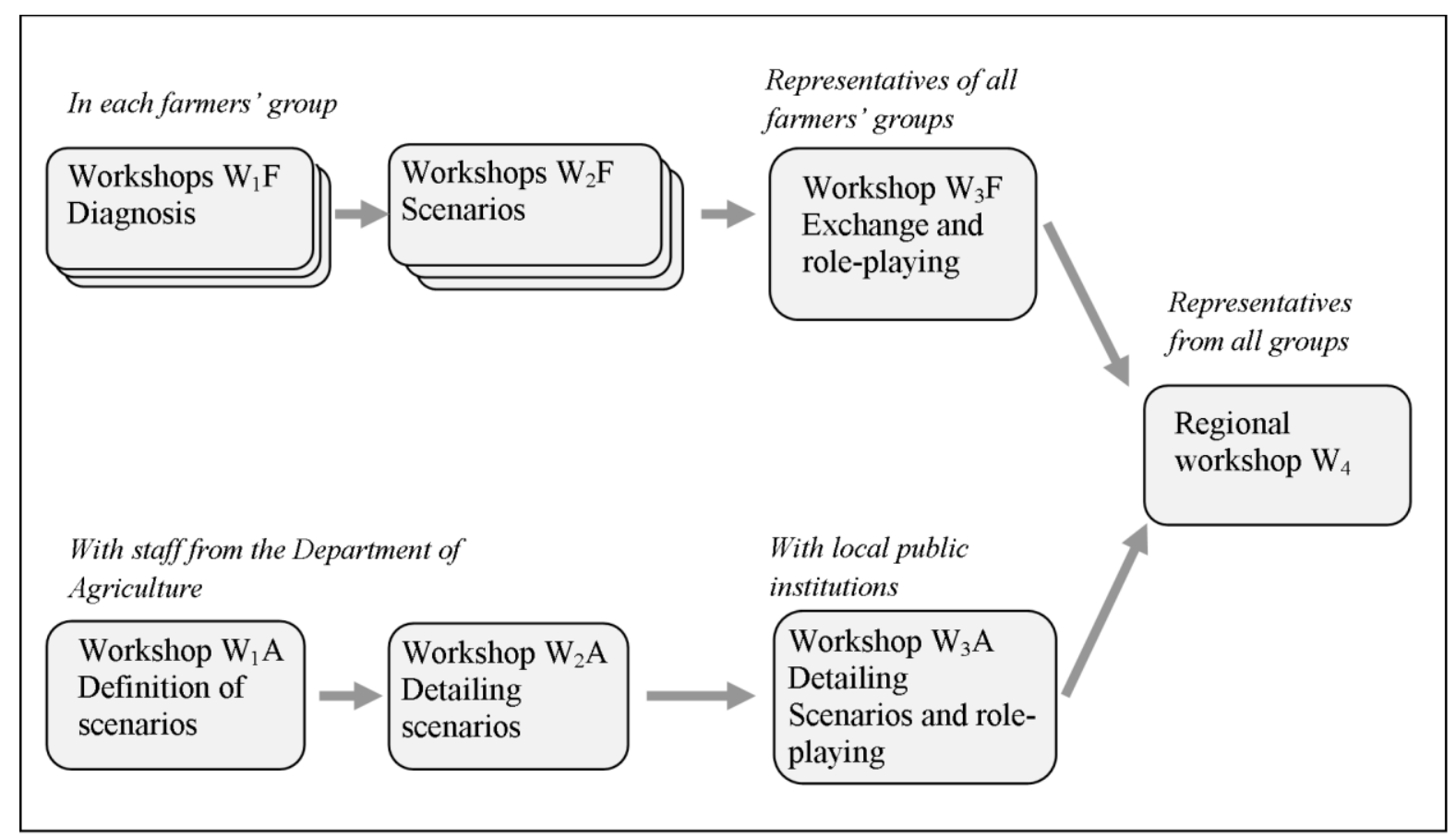

Figure 2. The multistakeholder process.

During workshop $\mathrm{W}_{3} \mathrm{~F}$, representatives of the three farmers' groups discussed the results of their previous work, made a joint assessment at the regional level, and outlined strategies to cope with the groundwater and agricultural crisis. They then took part in a role-playing game to improve their understanding of the roles of the main public and private organizations in the area, of the resources available to the organizations and the constraints they faced. Participants played the roles of local administrators from the DoA, the catchment management agency, and the dairy industry. They had to define and coordinate intervention plans, first in a period of abundant water with marketing problems and then in a period of severe drought and a groundwater crisis.

Workshop $\mathrm{W}_{3} \mathrm{~A}$ was for representatives of the catchment management agency, the DoA and local municipalities. Participants assessed groundwater resources and the agricultural sector. They also took part in a role-playing game that aimed at a more field oriented discussion, in order to avoid wishful thinking. Participants played the roles of farmers in the region. Finally, participants discussed and refined the scenarios prepared by the DoA staff during the first workshops, together with possible strategies to face the agricultural crisis.

During the final workshop, a farmers' representative and a representative of the DoA group presented the work accomplished during the previous workshops in terms of assessment, scenarios, and possible actions for tackling the main problems. Then, in small groups, participants discussed the actions proposed by both farmers and DoA staff in three main topic areas (water, marketing, and the supply of inputs). This was followed by a wrap-up session.

At the end of the final workshop, seven farmers and seven staff members of public organizations were invited to score several aspects of the process using poor (0), average (1) or good (2). Ex-post interviews were also conducted with participants who had been involved in most stages of the process, i.e., seven farmers (two or three from each group) and six engineers from the DoA. In both cases the relevance of the process, the quality of the method, the learning that took place, and the added value of the ideas produced during the workshops were discussed. 


\section{Results}

\section{Workshop Implementation and Results}

In the $\mathrm{W}_{2} \mathrm{~F}$ workshops, all the farmers' groups identified access to water as the single most important factor for change. In Groups $G_{A}$ and $G_{B}$, in scenarios of the future, this amounted to whether future rainfall would be sufficient or not. If future rainfall turned out to be sufficient, most farmers in Groups $\mathrm{G}_{\mathrm{A}}$ and $\mathrm{G}_{\mathrm{B}}$ planned to increase vegetable production, and in the event of successive droughts, to shift to cattle rearing (in this region the most common forage is rainfed maize). In Group $\mathrm{G}_{\mathrm{C}}$, the single most important factor for change was whether the village would be connected to a planned drinking water supply network. This connection would enable them to water their animals, especially cows, which were affected by drinking saline water. Farmers in Group $G_{C}$ planned to increase cattle and chicken rearing if they were connected to the water network and thought they would need to look for off-farm employment if this did not happen. All the groups considered these factors to be extremely uncertain, and, in the farmers' opinion, would lead to quite different paths of change at the farm and village levels. The other main factors for change were the prices they obtained for their farm products and the cost and quality of inputs. Here, the issues discussed were not so much the variety of possible futures, which would all lead to an increase or a decrease in the production of market crops; instead, discussions with farmers focused on identifying actions to resolve difficulties in the supply of inputs and in marketing their products.

In workshop $\mathrm{W}_{3} \mathrm{~F}$, the three farmers' groups agreed on a common analysis of the area and of the actions needed to solve the problems related to water access, inputs, and marketing. They found no difficulty in conducting assessments at the scale of the whole study area.

The DoA staff constructed four scenarios. The first two scenarios concerned only Zone A and assumed the irrigation scheme would be constructed. The first scenario involved no specific support for small-scale farmers and assumed their subsequent disappearance to the benefit of large-scale capital-based farms. The second scenario included a range of policies to ensure the economic sustainability of small-scale farms located within the irrigation scheme. The two remaining scenarios covered the whole area and assumed that the irrigation scheme would not be built. The third scenario was a business-as-usual scenario, with no public action to help farmers adapt to the groundwater crisis. This led to a major decrease in irrigated farming. The fourth scenario was based on a series of actions designed to support farmers in adapting to the scarcity of fresh groundwater.

In the farmers' role-playing game, the participants learned about the functions and means available to the main organizations responsible for the management of agriculture and water resources in the area. The role-playing game with the staff of public organizations helped the participants take a broader view of existing policies for agriculture and water resources management in the region. In planning the development of farms during the game, the staff, acting on their own initiative, ignored existing policies. In particular, the regional action plan did not include dairy activities. In the game, all the participants considered such activities to be an indispensable part of a risk reduction strategy at farm level. As a participant told us later: "when you play the role of a farmer, you can't be sure the administration is actually going to do anything". This activity helped legitimize the importance of the dairy sector for the region in subsequent discussions.

During the final workshop, the farmers and DoA staff engaged in open and constructive discussion, particularly in the sessions in small groups. Farmers and the DoA staff generally 
agreed on the main development issues. Farmers thought that the scenarios they had built based on the evolution of some factors of change were largely compatible with the more global scenarios drafted by the DoA staff. However, the farmers and the DoA staff differed on some of the proposed actions (Table 1). In particular, in the light of past failures, the farmers' enthusiasm for the DoA's proposal to re-establish export channels was lukewarm. Most farmers preferred the creation of a daily market in the center of the area, so they would be able to bring their products to market more easily and be in a better position to discuss prices with middle men. Farmers also emphasized their interest in developing dairy farming. Group $G_{C}$ described their attempts to become connected to a rural drinking water system. These projects had not been considered by the DoA staff.

Table 1. Main actions suggested during the final workshop

\begin{tabular}{lll}
\hline Water & Irrigation scheme & Farmers \\
\hline Marketing & $\begin{array}{l}\text { Irrigation scheme, connecting the } \\
\text { village to the drinking water supply } \\
\text { network for watering animals, water } \\
\text { desalinization, growing crops that are } \\
\text { tolerant to salinity }\end{array}$ \\
& $\begin{array}{l}\text { Trade Office, support for new } \\
\text { cooperatives for marketing } \\
\text { vegetables on the national } \\
\text { market }\end{array}$ & $\begin{array}{l}\text { Creation of a daily local market for } \\
\text { vegetables, dairy cooperatives, and } \\
\text { fixed prices for wheat to be sold to } \\
\text { the national wheat marketing } \\
\text { cooperative }\end{array}$ \\
Inputs & $\begin{array}{l}\text { Quality control and fixed prices for } \\
\text { inputs }\end{array}$ \\
Catthers & meat, poultry, rainfed orchards & $\begin{array}{l}\text { Better state support: better } \\
\text { information on existing subsidies, } \\
\text { and simpler administrative } \\
\text { procedures }\end{array}$ \\
&
\end{tabular}

\section{Participants' Evaluation of the Process}

All the participants at the final meeting emphasized their interest in the process (in the questionnaire they filled in, all the participants interviewed gave a score of 2, i.e. a positive evaluation, for relevance). Farmers and staff scored the creation of a space for dialogue with an average of 1.6 and 1.7 respectively.

Farmers appreciated the quality of the discussion with the DoA staff, underlining the contrast with previous encounters. However, they also pointed out that such a process would only be useful if it subsequently led to the implementation of the actions discussed. The DoA staff underlined the quality of the discussions with farmers, who, contrary to their expectations, had not come to complain but to make suggestions and to discuss on a peer-to-peer basis. The DoA staff also appreciated the quality of the process per se: they valued the opportunity for open discussion of desirable developments and of the relevance and practicality of certain actions in the regional action plan. They were more enthusiastic than the farmers about the 
method used. The farmers and staff of public institutions scored the relevance of the methods and tools used 1.6 and 1.8 respectively. The DoA staff appreciated meeting other organizations such as the catchment management agency, with whom they almost never had contact. The DoA staff also pointed out that the preliminary analysis could have been more detailed, and that the three communities selected were not representative of the diversity of the situations in the area. Farmers scored the involvement of all stakeholders with an average of 1.7, but the DoA staff scored it only with an average of 1.4.

The staff of the DoA and the farmers also evaluated the learning that took place during the process. An average score of 1.8 for collective learning was given by both groups. The process enabled a move from initial assessments by the DoA staff of either complete acceptance or complete rejection of the possibility of successful implementation of the regional action plan, to positioning its implementation as one possible scenario among others. However, the DoA staff considered that they had learned more about the methods used to support group discussions than about the actual ideas that were discussed. Farmers stated that they learned about the functioning of public organizations, especially thanks to the roleplaying game. However, even though they acknowledged improvements in the way they discussed with staff of public organizations in the final meeting, they considered that one meeting was not sufficient to alter their view of public institutions. An average of 1.1 was given by farmers for a change in their opinion about other actors, while an average of 1.4. was given by the staff of public institutions .

Despite participants' positive assessments, there was no follow-up to the discussions. The farmers' organizations and local municipalities lacked the ability to lead such a dialogue and the catchment management agencies did not consider the issue a priority. The DoA did have sufficient staff to maintain such a dialogue, but had no responsibility and limited interest in doing so.

\section{Discussion}

The actions proposed by the farmers and the DoA staff did not represent radical changes from the existing situation. The actions did not include direct management of groundwater, e.g., limiting the drilling of new boreholes. The actions considered did not involve off-farm activities such as tourism. Thus, farmers and the DoA remained focused on coping strategies (Osbahr et al. 2008), both in terms of the time scale and the types of actions and economic activities they considered.

All the actions proposed are likely to improve the farmers' capacity for coping with the groundwater crisis in the short term, by providing alternative water resources, by decreasing the vulnerability of farming systems to groundwater, or by increasing the profitability of production systems. Some of the actions discussed in the final workshop may reduce groundwater use, in particular the development of rainfed orchards, poultry, and alternative water supply systems. The impact of increased dairy farming on groundwater use was not clear, since farmers may rely on rainfed forage crops but may also irrigate them, especially since maize can tolerate irrigation with brackish water. Setting up a local market and improving the supplies of inputs were likely to increase the profitability of existing vegetable production systems. Consequently, these two actions may not reduce (and may even increase) the use of groundwater. These actions, if implemented alone, would thus not reduce the longterm vulnerability of the social-ecological system (see Berahmani et al. 2012 for further discussion on this aspect). 
The dialogue thus faced several limits that prevented it from triggering social learning: a lack of perspective on long-term sustainability; too brief interactions between the different actors; and the absence of diffusion of learning to wider social units (Reed et al. 2010). Despite these limitations, farmers and staff of public organizations improved their understanding of each other's interests and their opinions largely converged on the diagnosis of the ongoing crisis. The process led participants to question their assumption that genuine and fruitful discussions with their "counterparts" (either farmers or the public organizations) were impossible. This means one less stumbling block on the road to social learning in the Chaouia region.

A multi-stakeholder process to enable social learning should explicitly deal with the three characteristics of social-ecological systems that resulted in weak governance in the Chaouia region. Dealing with the first characteristic (actors' limited capacity to interact with each other) means organizing a longer multi-stakeholder dialogue, which would provide space and time for stable groups of farmers to interact with staff from public organizations and learn to exchange viewpoints. Dealing with the second characteristic (actors' limited interest in being involved in the management and limited trust) could combine assessment of long-term strategies to enhance the resilience of the social-ecological system (including tackling the issue of how to ensure sustainable use of groundwater) with interacting with short-term development projects to ensure the continued interest of farmers. Ensuring the involvement of senior staff of the DoA and the catchment management agency would also be necessary. The third characteristic (difficult and costly implementation of direct control of the uses of natural resources) calls for a wider array of actors being involved in the process, including actors who are able to assess strategies that could act and have an impact beyond the field of water resource management (Shah 2009). A longer period of multi-stakeholder dialogue and a wider range of actors participating in the dialogue would facilitate the diffusion of learning to wider social units.

\section{Conclusion}

The process described here enabled a productive, though short-lived, dialogue among local stakeholders in a situation of weak governance. The preliminary analysis was a key element in assessing constraints to dialogue between the actors, and made it possible to design a multi-stakeholder process that took into account how to overcome these constraints. The dialogue process described in this paper paved the way for social learning in a situation of weak governance of the social-ecological system, by challenging the pessimistic assumptions of actors about the possibility of productive collective thinking, and by clarifying what may be needed to make social learning possible in such unfavorable circumstances. Even more than in situations of less weak forms of governance, these ways require adopting a "strategic approach" to social learning, as advocated by Röling and Maarlveld (1999).

\section{Acknowledgements}

The study was part of the Aquimed project, which took place in the framework of the Eranet Circle-Med initiative. It was funded by the French Ministry of Ecology, Energy and Sustainable Development. The authors thank the farmers and staff of the Moroccan 
Department of Agriculture and Sea Fishing who participated in the study. We are grateful for the comments and suggestions made by three anonymous reviewers.

\section{References}

Armstrong, P. 1994. Human rights and multilateral development banks: Governance concerns in decision making. Proceedings of the Annual Meeting of the American Soc. of Int. Law $88: 277-282$.

Baldwin, C., and H. Ross. 2012. Bridging troubled waters: Applying consensus-building techniques to water planning. Sociey Nat. Resources 25(3):217-234.

Bento, S., F. Driouech, M. Errahj, N. Faysse, P. Garin, A. Richard Ferroudji, J.D. Rinaudo, D. Rollin, L. Schmidt, and M. Varanda. 2009. Farmers' relations to climate variabilities and changes: The case of groundwater users of coastal aquifers in France, Portugal and Morocco. Paper presented at the ninth conference of the European Sociological Association, Lisbon, Sept, $3^{\text {rd }}$.

Berahmani, A., N. Faysse, M. Errahj, and M. Gafsi. 2012. Chasing water: Diverging farmers' strategies to face the groundwater crisis in the coastal Chaouia region in Morocco. Irrigation and Drainage 61(5): 673-681.

Ducrot, R. 2009. Gaming across scale in peri-urban water management: Contribution from two experiences in Bolivia and Brazil. Int. J. of Sust. Dev \& World Eco. 16(4):240-252.

Fakir, Y., A. Zerouali, M. Aboufirassi, and M. Bouabdelli. 2001. Exploitation et salinité des aquifères de la Chaouia Côtière, littoral atlantique, Maroc [Potential exploitation and salinity of aquifers, Chaouia coast, Atlantic shoreline, Morocco]. J. of African Earth Sciences 32(4):791-801.

Faysse N., M. El Amrani, S. El Aydi, and A. Lahlou. 2012a. Formulation and implementation of policies to face groundwater overuse in Morocco: Which supporting coalitions? Irrigation and Drainage 61:126-134.

Faysse, N., J.D. Rinaudo, S. Bento, A. Richard-Ferroudji, M. Errahj, M. Varanda, A. Imache, M. Dionnet, D. Rollin, P. Garin, M. Kuper, L. Maton, and M. Montginoul. 2012b. Participatory analysis for adaptation to climate change in Mediterranean agricultural systems: Possible choices in process design. Reg. Env. Change 10.1007/s10113-012-0362-x. 
Gidley, J.M., J. Fien, J.A. Smith, D.C. Thomsen, and T.F. Smith. 2009. Participatory futures methods: Towards adaptability and resilience in climate-vulnerable communities. Env. Policy and Governance 19(6):427-440.

Greenwood, D.G., and M. Levin. 2007. Introduction to action research: Social research for social change. Thousand Oaks, CA: Sage.

March, H. O. Therond, and D. Leenhardt. 2012. Water futures: Reviewing water scenario analyses through an original interpretative framework. Ecological Economics 82:126-137.

Mostert, E., C. Pahl-Wostl, Y. Rees, B. Searle, D. Tàbara, and J. Tippett. 2007. Social learning in European river-basin management: Barriers and fostering mechanisms from 10 river basins. Eco. Soc. 12(1):19.

Muro, M., and P. Jeffrey. 2012. Time to talk? How the structure of dialog processes shapes stakeholder learning in participatory water resources management. Eco. Soc. 17(1):3.

Muro, M., and P. Jeffrey. 2008. A critical review of the theory and application of social learning in participatory natural resource management processes. J. of Env. Planning and Management 51(3):325-344.

Osbahr, H., C. Twyman, W.N. Adger, and D.S.G. Thomas. 2008. Effective livelihood adaptation to climate change disturbance: Scale dimensions of practice in Mozambique. Geoforum 39:1951-1964.

Ostrom, E. 1990. Governing the commons. The evolution of institutions for collective action. Cambridge: Cambridge University Press.

Rametsteiner, E. 2009. Governance concepts and their application in forest policy initiatives from global to local levels. Small-Scale Forestry 8(2):143-158.

Ravera, F., D. Tarrasón, and E. Simelton. 2011. Envisioning adaptive strategies to change: participatory scenarios for agropastoral semiarid systems in Nicaragua. Eco. Soc. 16(1):20.

Reed, M. S., A. C. Evely, G. Cundill, I. Fazey, J. Glass, A. Laing, J. Newig, B. Parrish, C. Prell, C. Raymond, and L. C. Stringer. 2010. What is social learning? Eco. Soc. 15(4):r1.

Rist, S., M. Chiddambaranathan, C. Escobar, and U. Wiesmann. 2006. "It was hard to come to mutual understanding ..."- the multidimensionality of social learning processes concerned with natural resource use in India, Africa and Latin America. Syst. Practice Action Research 19(3):219-237.

Röling, N., and M. Maarleveld. 1999. Facing strategic narratives: An argument for interactive effectiveness. Agriculture and Human Values 16: 295-308. 
Rogers, P., and A.W. Hall. 2003. Effective water governance. Global Water Partnership Technical Committee Background Paper No. 7. Stockholm, Sweden: Global Water Partnership.

Ross, A., and P. Martinez-Santos. 2010. The challenge of groundwater governance: Case studies from Spain and Australia. Reg. Environ. Change 10(4): 299-310.

Shah, T. 2009. Taming the anarchy: Groundwater governance in South Asia. Washington, D.C., USA: Resources for the Future Press.

Steyaert, P., and J. Jiggins. 2007. Governance of complex environmental situations through social learning: A synthesis of SLIM's lessons for research, policy and practice. Env. Science \& Policy 10(6): 575-586.

Sultana, P., and P. Thompson. 2004. Methods of consensus building for community-based fisheries management in Bangladesh and the Mekong Delta. Agricultural Systems 82(3):327353.

Theesfeld, I. 2010. Institutional challenges for national groundwater governance: Policies and issues. Ground Water 48(1):131-142.

Van Steenbergen, F. 2006. Promoting local management in groundwater. Hydrogeology J. $14: 380-391$.

Younsi, A., J. Mania, E.K. Lhadi, and J. Mudry. 2001. Incidences de pluies exceptionnelles sur un aquifère libre côtier en zone semi-aride (Chaouia, Maroc) [Influence of extreme rainfall events on an unconfined coastal aquifer (Chaouia, Morocco)]. Revue des sciences de l'eau 14(2):115-130. 